\title{
Notas não sobre, mas Em uma espécie de cinema
}

\author{
Notes not about, but \\ In a kind of cinema
}

Filipe Manzoni ${ }^{1}$

Há uma curiosa polêmica a respeito da data e do local da invenção do cinema. De um lado, temos a data mais comumente aceita, a primeira projeção pública de um cinematógrafo, feita pelos irmãos Lumière em Paris, 28 de dezembro de 1895. De outro lado, há um contra-argumento que funda o cinema até seis anos antes, nas gravações e execuções experimentais feitas por Thomas Edison e sua equipe, inventores do cinetógrafo e do cinetoscópio, em seus laboratórios nos Estados Unidos, entre 1889 e 1891.

Mais do que apenas uma disputa pelo pioneirismo, o que está em jogo são duas concepções do que venha a ser, efetivamente, o cinema. Se seguirmos a versão americana, teremos o nascimento do cinema vinculado à invenção do aparato técnico de gravação e reprodução de imagens de maneira a causar uma impressão de movimento contínuo. Se, ao contrário, seguirmos a celebrada data de nascimento francesa, teremos a gênese do cinema como a formatação de um espetáculo estético de projeção exibido para um público pagante, ou ainda, teremos a invenção da experiência do cinema (e de sua comercialização) como ainda a conhecemos.

Trata-se, portanto, de uma distinção particularmente relevante para a tentativa de desvinculação do cinema de seu "formato mercadoria", mas que dificilmente mantém seus contornos opositivos assim tão nítidos após mais de um século da cinematografia como provavelmente a mais

Professor de Literatura Brasileira da Universidade Federal do Rio de Janeiro. 
bem sucedida arte de massa. De fato, a especificidade técnica do suporte medial e o ritual de fruição - a "mágica" da sala de projeção - parecem estar hoje tão contaminados um pelo outro e tão fortemente arraigados na experiência comum que, frequentemente, é a partir de uma aisthesis já moldada pela experiência cinematográfica que empreendemos qualquer tentativa de definição do cinema. É algo que salta aos olhos, por exemplo, quando lemos um poema como Cinemas King (sessão da meia-noite), de José Mário Silva, incluído na recente antologia brasileira e portuguesa, Uma espécie de cinema (2019):

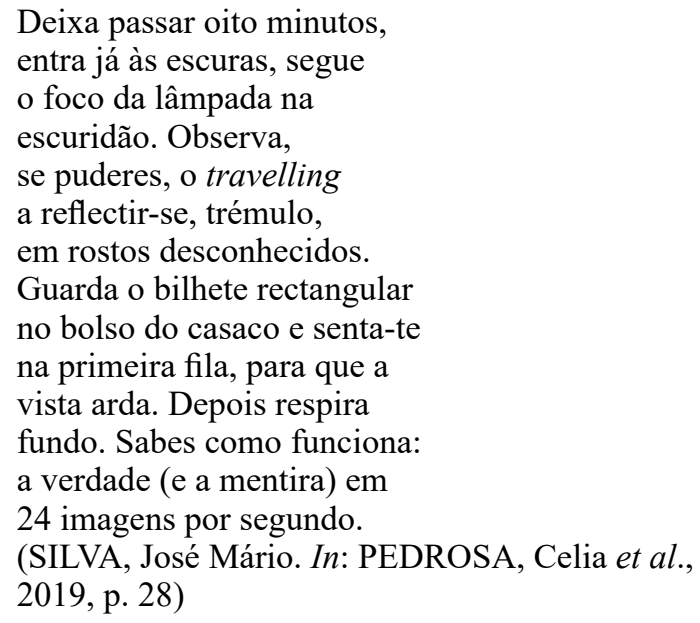

Desde os primeiros quatro versos do poema, José Mário Silva narra uma espécie de percurso-convite cinematográfico pelo próprio espaço da sala de projeção - não qualquer sala de projeção, mas o icônico Cinema King de Lisboa, por onde passaram clássicos da sétima arte até sua desativação em 2013. Nosso olhar é guiado por uma voz que lê o próprio trajeto pela sala desde códigos cinematográficos, alternando entre um travelling inicial, o close no bilhete no bolso e - arriscaria, talvez, um olhar viciado pelas câmeras - um plongée e contra-plongée no movimento de sentar-se na primeira fila e direcionar o olhar para a tela. Mais do 
que sobre o cinema, trata-se de um poema desde o cinema, no cinema e em direção ao cinema (tomado enquanto código, espaço e experiência, respectivamente).

Cinemas King não é, porém, nenhuma exceção dentro dos cem poemas que compõem a antologia Uma espécie de cinema, lançada no segundo semestre de 2019 pela oficina Raquel: não uma antologia sobre, mas sim desde, em e até o cinema. Em verdade, é difícil falar "cinema" no singular dentro do volume, já que o que predomina nos setenta e três poetas reunidos - quarenta e um brasileiros e trinta e dois portugueses - é a heterogeneidade. Ainda que a antologia estabeleça, por exemplo, um recorte cronológico, reunindo apenas textos publicados a partir dos anos 90, não se trata de uma delimitação geracional. Encontramos textos de veteranos como Herberto Helder ou Manoel de Barros, figuras que já eram amplamente reconhecidas antes mesmo do nascimento de escritores mais novos como Walter Gam ou Ismar Tirelli Neto. Como resultado, escritores canônicos aparecem ao lado de poetas que provavelmente serão lidos pela primeira vez, assim como poemas de obras de estreia figuram ao lado de fragmentos das últimas publicações de algumas longas e sólidas carreiras de produção poética, tudo isso contribuindo para uma flagrante heterogeneidade na qual a experiência do cinema pode significar coisas muito diferentes.

Quanto à relação mesma entre poesia e cinema, a apresentação, assinada pelos seis organizadores, Celia Pedrosa, Franklin Alves Dassie, Joana Matos Frias, Luciana di Leone, Luís Miguel Queirós e Rosa Maria Martelo - vários deles figuras recorrentes no circuito de discussão sobre poesia e cinema -, deixa evidente o quanto, mais do que circunscrever um recorte crítico específico, o que interessa é abrir caminhos possíveis. Os poemas reunidos parecem construir uma espécie de campo de tensões no qual poesia e cinema figuram em uma pluralidade de salas de projeção, leituras de filmes que marcaram diferentes gerações, técnicas 
cinematográficas e sessões específicas que ficaram na memória.

$\mathrm{O}$ próprio título da antologia, retomado de um fragmento de Herberto Helder, é estratégico nesse ponto. Pensar a poesia como uma espécie de cinema parece contornar uma armadilha clássica e tão recorrente nas aproximações entre duas linguagens artísticas: a subscrição de um limite específico, pressuposto, mas não problematizado, para a oposição entre os dois discursos em questão. Em outras palavras: no lugar de um investimento em um paradigma da "hibridização" - um cruzamento entre duas espécies distintas -, ao situar a poesia como uma espécie de cinema, o que interessa é o problema da especiação mesma. Diferentemente, portanto, de uma negociação entre duas estruturas que se constroem de forma opositiva, quando partimos da possibilidade da distinção - ou seja, quando uma coisa é apenas um caso particular da outra - quanto mais caracteristicamente "si mesmo" mais também se é "uma espécie de outra coisa". Um poema especialmente interessante, nesse ponto, é Do Titanic no ecrã, de Fiama Hasse Pais Brandão:

\footnotetext{
"A poesia é uma loucura de palavras"*: golfadas de água, pistons, caldeiras, mar de silêncio, música de pianoforte, escadaria, ascensores, golfadas de água, trajos de gala, icebergs, mar de silêncio, amor, morse, foguetes de luz, música de pianoforte, amor, decotes, plumas, tules, icebergs, pistons, camarotes, madeira envernizada, tapeçarias, ascensores, morse, amor, mar de silêncio, salva-vidas, escaleres, escadas de corta, sino, apitos, foguetes de luz, golfadas de água, escaleres, jorros, mar de silêncio, morse, sino, escaleres, amores mortos, morse, morte, amor, morse - disse um grande poeta meu contemporâneo (BRANDÃO, Fiama Hasse Pais. In: PEDROSA, Celia et al., 2019, p. 55)
} 
Partindo de uma citação de Ruy Belo (conforme nos é revelado no pé-de-página), o poema constrói uma espécie de decupagem fragmentária de elementos reconhecíveis da sequência final do blockbuster de James Cameron. O que a poesia é, portanto - "uma loucura de palavras" -, é precisamente o que, dentro do poema, a aproxima do cinema enquanto tensão paratática de imagens e a afasta de um encadeamento sintático (de fato, a única coisa que mantém o encadeamento é a memória visual do filme). Caberia ainda manter em mente que é precisamente esse jogo de parataxe/sintaxe que fez a poesia servir inúmeras vezes de analogia para a proposição da montagem como elemento central da linguagem cinematográfica em alguns dos seus principais teóricos do início do século XX - não é difícil encontrar paralelos com a poesia nos diversos textos teóricos de Eisenstein dos anos 20 e 30, e Dziga Vertov, já em seu primeiro manifesto, Nós, fala também de uma "poesia da máquina" como forma de resgatar o cinema de sua cooptação pelos códigos do romance e do teatro. Tudo se passa, portanto, como se, em certa medida, fosse também como uma "espécie de poesia" que o cinema teorizasse sobre sua própria linguagem.

São diversos os poemas que se aproveitam de oscilações semelhantes entre poesia, cinema e suas diferentes teorizações em Uma espécie de cinema. Podemos apontar algumas composições poéticas que apresentam esse tipo de mesclagem: Metamorfoses, de Carlito Azevedo - no qual temos uma reflexão sobre a necessidade das 24 imagens por segundo se convertendo em uma espécie de teoria ampliada da continuidade, ilustrada finalmente por uma cena que deixa evidentes as marcas do universo cinematográfico -, Bushido de Fernando Guerreiro, no qual uma descrição cinematográfica - na qual aparecem gângsters e um yakusa bebendo absinto - se sobrepõe também a uma espécie de teoria do poema, ou ainda Cinemas, de Herberto Helder, uma teorização direta a respeito do cinema e seus "modos esferográficos de fazer e celebrar" 
(HELDER, Herberto. In: PEDROSA, Celia et al., 2019, p. 25).

É sintomático, nesse cenário de múltiplas e heterogêneas possibilidades de relação entre cinema e poesia, que a divisão interna da antologia em três blocos seja tanto proposta quanto subvertida já em sua apresentação. Os organizadores nos dizem o quanto nem sempre a distribuição dos poemas foi pacífica e "em certos casos teria sido perfeitamente possível proceder a uma organização diferente" (PEDROSA, Celia et al, 2019 p. 9). Mais do que como limites internos, a estrutura em três blocos parece oferecer-se, assim, como uma proposição de três campos de ressonância e contaminação: Indo ao cinema - que se volta para os poemas que traduzem uma relação com o espaço físico das salas de projeção - Depois do filme - em que aparecem diálogos, releituras e retomadas de filmes, cineastas, atores e personagens específicos - e finalmente Filmagens - no qual a relação com o cinema se constrói a partir de uma priorização das técnicas da linguagem cinematográfica.

De nossa parte, caberia ressaltar que essa divisão em três "câmaras de ecos" ainda possibilita que outras afinidades transversais sejam amplificadas. É impossível não reparar, por exemplo, lendo o primeiro bloco, na abundância de cenas de afeto e de convivência com o outro. Ir ao cinema se converte, em grande parte dos poemas, em um "ir ao cinema com", de maneira que amizades - como em [De mão dada] de Adília Lopes -, namoros e suas memórias -Aracne de António Franco Alexandre ou E de resto, Glaura? Tem ido ao cinema? de Rubens Rodrigues Torres Filho - ou ainda gerações inteiras marcadas por cinemas específicos - como o já citado Cinemas King ou ainda Geração Paissandú de Paulo Henriques Britto - parecem povoar o bloco com um tom especialmente afetivo. Tomemos, por exemplo, Cinema de Ana Martins Marques, no qual o ritual do "assistir com" extrapola o próprio espaço do cinema: 


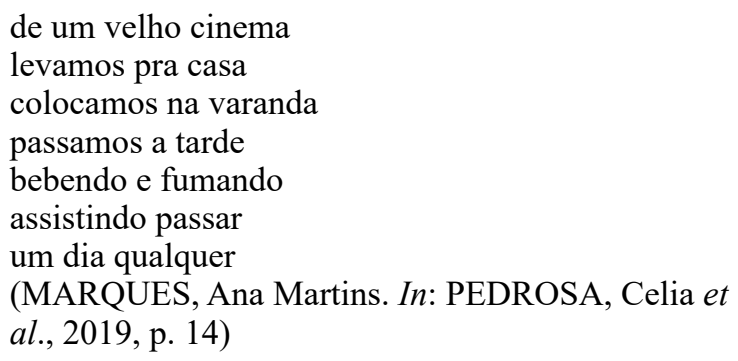

De maneira especialmente significativa para um cenário conceitual que, desde Benjamin, associa o cinema à queda da aura, a fileira de cadeiras parece trazer precisamente o rastro material de um "estar aí" da sala de projeção, transpondo a experiência mnemônica-afetiva do cinema para um transbordamento do ritual do "assistir" que permite converter um dia qualquer em um espetáculo estético (em 24 quadros por segundo, jamais nos 60 da televisão, tecnologia que parece incompatível com esse cenário: um sofá de sala de estar não nos convida a "assistir o mundo" da mesma maneira).

Se o primeiro bloco parece dizer de diferentes experiências em cinemas, essas experiências se particularizam em relação aos filmes assistidos no segundo núcleo, Depois do filme. Nele, predomina uma série de poemas que se apresentam como experiências de leituras e retomadas de filmes específicos, seja de maneira mais direta - como em Crítica de Miguel Gomes a Funny Games de Michael Haneke, de Daniel Jonas, ou Nuance entre lilases de Lu Menezes - seja de maneira quase tangencial - como em [Venho de nobres que empobreceram], de Manoel de Barros.

É interessante ainda que, em alguns poemas de Depois do filme, as retomadas de momentos ou figuras marcantes do cinema parecem converter-se em uma espécie de vocabulário afetivo a partir do qual se lê as mais diversas experiências, algo como uma "educação sentimental" cinematográfica. Tomemos o caso de um poema sem título de Arnaldo Antunes: 
porque eu te olhava e você era o meu cinema, a minha Scarlet

O'Hara, a minha Excalibur, a minha

Salambô, a minha Nastassia

Filípovna, a minha Brigite Bardot, o meu

Tadzio, a minha Anne, a

minha Lou Salomé, a minha Lorraine, a

minha Ceci, a minha Odete

Grecy, a minha Capitu, a minha

Cabocla, a minha Pagu, a minha

Barbarella, a minha Honey Moon, o meu

amuleto de Ogum, a

minha Honey Baby, a minha Rosemary, a

minha Merlin Monroe, o

meu Rodolfo Valentino, a minha

Emanuelle, o meu Bambi, a minha

Lília Brick, a minha Poliana, a minha

Gilda, a minha Julieta, e eu

dizia a você do meu amor e você ria, suspirava e ria.

(ANTUNES, Arnaldo. In: PEDROSA, Celia et al., 2019, p. 45)

O poema de Arnaldo é especialmente interessante para o percurso de leitura que viemos montando. Mais do que apenas incorporar um vocabulário imagético do cinema, o que se coloca é quase um modo "cinematográfico" de relação com as imagens como paradigma da declaração amorosa. Mesmo quando a comparação provém de outra linguagem ou de outro contexto de circulação - da literatura ou da música, por exemplo - o "modo de ver" - "porque eu te olhava" - parece trazer o tom de um fascínio característico do cinematográfico. De maneira semelhante ao que líamos no poema de Ana Martins Marques, a questão é a presença de um modo específico de olhar, um ver "como cinema".

Finalmente, o bloco final, Filmagens, é o mais extenso dentro de Uma espécie de cinema, quase metade do volume total. Aqui, o vocabulário, isto é, o que era da ordem de um léxico do cinema, parece dar 
lugar a uma semiótica do cinema, de maneira que se faz presente todo um espectro de experimentalismos com diferentes priorizações e apropriações da linguagem técnica cinematográfica. Encontramos desde analogias com o mecanismo de projeção, como, por exemplo, em Home movie de Eudoro Augusto, até a exaustão de mecanismos de corte e repetição - [uma cena se repete] de Annita Costa Malufe -, passando ainda por incursões nas especificidades do olhar guiado pela câmara, a exemplo de 6 movimentos de câmera, de Rodrigo Garcia Lopes.

Gostaríamos, finalmente, de fechar com um poema desse último bloco, da autoria de Ricardo Aleixo. Não tanto porque se trate de um poema mais representativo do núcleo como um todo (de fato, este deve ser o bloco mais heterogêneo da antologia), mas sim por crermos que ele possibilita uma espécie de reverberação final de nosso próprio esboço de leitura de Uma espécie de cinema.

Inserido imediatamente após Cine-olho - retomada, também de Ricardo Aleixo, do termo de Dziga Vertov -, o poema que nos interessa, Cine-ouvido, não se ocupa tanto de uma incorporação dos códigos cinematográficos - as imagens que aparecem "riscando" a tela em "Cineolho" - mas sim de uma espécie de internalização sinestésica de um "cinema interior". E aqui chegamos ao que nos interessa: Cine-ouvido parece levar a contaminação entre linguagem e experiência cinematográfica para um cenário muito especial, na medida em que traz para o primeiro plano o cinema que perdura mesmo com os olhos e ouvidos fechados, isto é, quando ainda lemos o cinema mesmo quando ele não está mais ali:

você fecha

os olhos e vê:

luzes pulsando

contra um

fundo sem cor

cobre os ouvidos 


\author{
e ouve: o eco \\ do pulsar \\ das luzes da \\ estrofe anterior \\ (ALEIXO, Ricardo. In: PEDROSA, Celia et al., 2019, p. 146)
}

\title{
Referências
}

PEDROSA, Celia; DASSIE, Franklin Alves, FRIAS, Joana Matos, LEONE, Luciana di, QUEIRÓS, Luís Miguel, MARTELO, Rosa Maria (org.) Uma espécie de cinema. Rio de Janeiro: Oficina Raquel, 2019.

Recebido em: 07/07/2020

Aprovado em: 05/08/2020 